REVISTA DE DERECHO UNED, NÚM. 18, 2016

\title{
FILOSOFÍA DEL DERECHO Y HUMANISMO EN DIALOGO CON LA ESPIRITUALIDAD. APUNTES PARA UNA ÉTICA SOLIDARIA DE LOS DERECHOS HUMANOS
}

\section{PHILOSOPHY OF LAW AND HUMANISM IN DIALOGUE WITH SPIRITUALITY. NOTES FOR A JOINT ETHICS OF HUMAN RIGHTS}

\section{Agustín Ortega Cabrera}

Autor para correspondencia: asortega@pucesi.edu.ec Docente e Investigador de la Pontificia Universidad del Ecuador Sede Ibarra (PUCE-SI)

Resumen: El presente trabajo recoge algunas reflexiones que hemos realizado en el ámbito del Departamento de Humanidades y Filosofía de la Universidad Loyola, en donde realizamos tareas de investigación. En las líneas de investigación sobre «Derechos humanos y transformación social» $\mathrm{y}$ «Matriz Cultural Ignaciana». Creemos que estas reflexiones y apuntes desde un pensamiento humanista, con un dialogo interdisciplinar, puede aportar alguna claves éticas solidarias para una Filosofía del Derecho. Lo cual contribuya a la promoción de los derechos humanos, de la justicia social y de la dignidad de la persona.

Abstract: This paper presents some reflections we have made in the field of Humanities and Philosophy Department at Loyola University, where we carry out research tasks. In the research on «Human rights and social transformation» and «Cultural Ignatian Matrix». We believe that these reflections and notes from a humanist thought, with an interdisciplinary dialogue, solidarity ethics can provide some clues 
for Philosophy of Law. Which contribute to the promotion of human rights, social justice and dignity.

Palabras clave: Filosofía del Derecho, Humanismo, Ética, Solidaridad, Derechos Humanos, Espiritualidad.

Keywords: Philosophy of Law, Humanism, Ethics, Solidarity, Human Rights, Spirituality.

Recepción original: 23/02/2016

Aceptación original: 6/04/2016

\section{INTRODUCCIÓN. UN HITO HISTÓRICO SIGNIFICATIVO}

El Departamento de Humanidades y Filosofía de la Universidad Loyola Andalucía celebró una Jornada de Investigación sobre el jesuita Francisco Suárez, uno de los pensadores más significativos de la historia de la cultura y de la iglesia. Junto a la Escuela de Salamanca encabezada por F. de Vitoria y testimoniada por Fr. Bartolomé de Las Casas, Suárez es uno de los exponentes más claros del conocido como humanismo renacentista. Con estos autores como el jesuita granadino, con este humanismo del Renacimiento, realmente comienza la edad moderna, lo más valioso de la modernidad. Y que luego será continuado por el ilustrado, con autores como Kant, aunque no con la misma valía que el de dichos pensadores renacentistas-humanistas. Inspirado todo este humanismo por la fe, en lo que se conoce como humanismo cristiano, que fue la génesis e inspiración del sentido de la persona, de su centralidad y dignidad, de los derechos humanos y del derecho internacional.

Desde la profundidad y actualidad del pensamiento de Suárez, se puede presentar toda una antropología que, con sus bases filosóficas y metafísicas, manifiesta una adecuada comprensión del ser humano en su realidad física, personal y social, ética y política. Una razón, conocimiento e inteligencia que contempla la verdad real, la realidad concreta, material, sociohistórica y, a la vez, que se abre e inter-relaciona con lo universal, con lo trascendente. Siguiendo a la tradición de la filosofía y teología, como Tomás de Aquino, Suárez presenta al ser humano en la perspectiva de la ley natural. Esto es, como está constituido y conformado la persona en su misma naturaleza o entraña más profunda, en sus inherentes dimensiones corporales y sociales, morales y espirituales. Lo que la mueve, la anima y dinamiza. Y que para la fe cristiana, es el sentido y esencia con el que Dios ha creado al ser humano, su proyecto de realización, de salvación liberadora en el Evangelio y Vida de Jesús. 
Como se observa y hemos apuntado, desde el pensamiento de Suarez nos situamos en plena tradición cristiana e ignaciana: en la contemplación y seguimiento de Jesús con la existencia moral-social; en el dialogo e inter-relación entre la espiritualidad y la vida, la mística y lo humano, la fe y la razón o la cultura. De esta forma, por esta naturaleza y constitución antropológica, el ser humano está llamado a ser libre; a la libertad que se realiza desde esta vida espiritual y moral en las circunstancias, en la realidad concreta y comunitaria, social e histórica. En este principio y fundamento que lo conforma, como nos muestra la fe -el mismo S. Ignacio-, la persona es libre, liberada y liberadora de toda esclavitud, mal e injusticia. El ser humano está vocacionado a la co-relación con el Otro y con los otros, a la acción de gracias del don recibido y al servicio a la humanidad, al mundo y a Dios en el bien más universal.

En el camino de la antropología filosófica o cristiana-teológica, y frente al posterior individualismo del liberalismo economicista que pervirtió la concepción de la libertad real, el ser humano es por naturaleza un ser comunicativo y religado a los otros. Es un ser comunitario, social y político. Y la libertad verdadera, la vida pública y cívica, se efectúa en la comunidad social. La sociedad civil es el sujeto y protagonista primero, principal de gobierno o gestión de las relaciones sociales, políticas y jurídicas o institucionales. La autoridad primigenia reside en la comunidad civil y social, en los pueblos que se dotan, en su vida sociopolítica y jurídica, de las formas de gobiernos y responsables institucionales para el servicio al bien común, a la libertad y a la justicia.

Si estas leyes, formas de gobierno o gobernantes no realizan el bien común, si se oponen a la naturaleza humana, libre y moral a la que está llamada toda persona: se tiene el derecho y deber de resistencia cívica a dichas autoridades o gobiernos injustos e inmorales; hay que oponerse a estos gobernantes y leyes que vayan en contra del bien común, de la ética y de la justicia. Para sustituirlas por otras más morales, más humanas y justas. Como se ve, frente a una concepción maquiavélica y liberal economicista-capitalista, desde la tradición moral y cristiana, Suárez siempre sitúa las relaciones sociales y políticas, económicas e internacionales en este marco antropológico y ético. Con los valores y principios morales de la verdadera libertad en el bien común, en la justicia y el valor-dignidad de las personas. Los gobiernos y las leyes siempre han de respetar al ser humano, la dignidad de las personas, sus necesidades y dimensiones, el desarrollo liberador de los pueblos. 
La antropología y humanismo ético suareciano posibilita la adecuada inter-relación entre la persona y la comunidad sociopolítica. Frente al liberalismo capitalista, el ser humano se encuentra vocacionado al servicio y responsabilidad moral por el bien común, la solidaridad fraterna y la justicia liberadora de toda injusticia u opresión. Y contra los colectivismos o estatalismos, la comunidad política o de gobierno no puede impedir ni negar la libertad, el protagonismo y gestión responsable de las personas o de los pueblos. Como se puede comprobar, Suarez pone las bases antropológicas y ética-políticas para una firme fundamentación de los derechos humanos, de los pueblos y del derecho internacional. Es una antropología y ética universal, cosmopolita que busca unas relaciones internacionales justas, liberadoras entre todas las naciones y pueblos de la tierra. Con el derecho de acción e intervención política internacional, cuando no se cumpla con la justicia y derechos. Él fue un pionero y artífice de la Doctrina Social de la Iglesia, de otro mundo global necesario.

\section{FILOSOFÍA DEL DERECHO DESDE UNA ÉTICA HUMANISTA PARA LA ACCIÓN-TRANSFORMACIÓN SOCIAL Y LOS DERECHOS HUMANOS}

Como nos muestra lo más valioso de la filosofía y de la teología, del pensamiento social inspirado en el cristianismo, la entraña del derecho es realizar la justicia en la realidad social e histórica. Esto es, para no caer en un idealismo e individualismo, el derecho real que implanta la justicia ha de socializarse e historizarse, lo que significa promover la liberación integral de los pobres, oprimidos y excluidos.

Si el derecho siempre tiene como claves: la alteridad, a las otras personas con su sagrada e inviolable dignidad; y la materialidad, las condiciones humanas y sociales, el bien común, que se han de restituir o asegurar. Entonces, la justicia que debe establecer el derecho se realiza desde los pobres, desde los sin derechos u oprimidos. Ya que los pobres, oprimidos y excluidos son las personas y pueblos a las que, real e históricamente, se les niega el bien común y padecen el mal común. Es decir, sufren unas condiciones humanas y sociales indignas que impiden la vida, dignidad y derechos

En esta línea, como nos enseña la filosofía, las ciencias sociales o humanas y la teología, por ejemplo el pensamiento social cristiano, cada una desde su especificidad, la acción y transformación social pertenece a la esfera de la ética y la antropología. La persona es un ser en inter-relación con los otros, es constitutivamente un ser social, cultural 
e histórico, es pues un ser político. Ya que para ser persona hay que dar sentido y orientación a estas relaciones sociales, públicas e históricas. Y se hace por la acción social y política que es la virtud moral en la vida social, pública para la búsqueda del bien común y la justicia que configuren u ordene la sociedad e historia.

Como vemos, la vida humana y ética es constitutivamente social y política, en la entrega y servicio al bien común, a la paz y la justicia social, liberadora con los pobres de la tierra (empobrecidos, oprimidos y víctimas de la historia). Esta vida moral en la ética social y política por el bien común y la justicia con los pobres, junto a (unido inseparablemente a) la contemplación-meditación y reflexión de la existencia (sabiduría espiritual), es lo que va realizando la felicidad personal y sociopolítica. En esta línea, no hay felicidad personal sin felicidad social y política. Es decir, sin entregarse, servir y comprometerse éticamente por la justicia con los pobres, por el bien común en la promoción de las condiciones humanas, sociales y políticas que posibilitan, a su vez, la felicidad personal, moral y espiritual.

Como se observa, la acción social supone una antropología y espiritualidad. Una comprensión concreta del ser humano con su búsqueda del sentido y trascendencia en la vida e historia, de valores y principios, de emociones y sentimientos, etc. De esta forma, nos alejamos profundamente de la acción social y política en su concepción individualista, utilitarista y maquiavélica que es la que predomina hoy. Como impone el neoliberalismo-capitalismo, es una acción social y política que se entiende como búsqueda del interés individual y del poder, como técnica y forma de fuerza, dominio y violencia para salvaguardar este poder económico y político a toda costa.

Contra el neoliberalismo y capitalismo que, como se ve claramente, es por esencia inhumano e inmoral, hay que promover la antropología comunitaria, solidaria e integral que, subrayamos, es la base de la ética social y política. Esto es, la antropología y ética social, política que busca el bien común, la paz y la justicia con los pobres, la fraternidad y la civilización del amor. Un desarrollo humano y social, integral y global de todas las dimensiones de cada persona. Es una ética y desarrollo universal, en solidaridad y justicia mundial con toda la humanidad, un desarrollo liberador con los pobres de la tierra, en una ética global y cosmopolita. Frente a todo individualismo y dinámica o realidad de injusticia, opresión y exclusión.

En esta línea, ante una mala reacción o respuesta al individualismo e injusticia primera del capitalismo con su liberalismo economicista-posesivo y mercantilista, tal como fue el comunismo colectivista 
o colectivismo (de tipo leninista-stalinista), hay que salvaguardar la libertad y protagonismo de la persona.

La persona es un ser llamado a la libertad y a la participación social, a ser protagonista de la vida pública, social y económica, ser gestora de la democracia. Y ningún estado, partido o agrupación política puede imponer a su libertad, a su vida y conciencia, que es sagrada, unos valores, formas de vida y principios: que no respeten esta vida digna, moral y liberadora de la persona; que no posibiliten una democracia participativa, real y co-gestionada por todos los grupos o comunidades humanas, sociales y espirituales o religiosas.

Así, son básicos consolidar los conocidos como derechos humanos de primera generación. Tales como la libertad de asociación, económica -con el derecho a propiedad personal-y empresarial, la libertad religiosa y moral, a elegir las formas de educación, comunitarias o sociales y éticas.

El Estado no puede ni debe hacerlo todo y siempre de forma directa, debe respetar e impulsar el derecho de subsidiariedad por el que las diversas instituciones, grupos y organizaciones sociales, como las familias que es célula vital de la sociedad, son participantes y protagonistas de su existencia. Si no se hace, se cae en totalitarismos y dictaduras como el colectivismo. Y todo ello se realiza en el marco de la ética social y política, del bien común y la justicia con los pobres que debe respetar la vida digna, los derechos humanos y el destino universal de los bienes para toda la humanidad.

Como se observa, frente al capitalismo y su dictadura del mercado con su neo-liberalismo del individualismo posesivo, en lo social y político se deben asegurar siempre la solidaridad, la justicia global con los pobres y la igualdad social, los llamados derechos humanos de segunda generación.

Los derechos sociales o socio-económicos, inviolables y de calidad, para toda persona. Como son la educación y la cultura. La sanidad y los medicamentos. La vivienda y un trabajo decente. Una renta básica y un sistema fiscal justo donde contribuyan más los que más tienen, los patrimonios más altos y capitales, las empresas multinacionales y la banca, corporaciones u operaciones financieras-bancarias.

Unos servicios sociales generales y especializados. Como ha estudiado la filosofía y las ciencias sociales y como recoge todo orden social, jurídico y constitucional ético, se trata de garantizar el estado social de derechos. Con un trabajo digno y un salario justo por encima del capital; una economía y empresa humanizada, democrática y 
co-gestionada, con responsabilidad social y ética. Una justa distribución de los bienes y recursos que está por encima de la propiedad privada. Ahora, frente al colectivismo o la social-democracia, este estado social no puede ser paternalista, burocrático y estatalista. Lo que impide la libertad, subsidiariedad y participación democrática en el protagonismo de la sociedad civil y de las comunidades éticas o espirituales. Frente a toda dictadura de estado y partido.

Tal como se ve, la acción social y política, la democracia, son mucho más (como se suele creer o decir) que solo la voluntad de las mayorías o el imperio de la ley. La actividad social, política y democrática se funda y realiza en el protagonismo, vida y dignidad inviolables de las personas, en la ética y en los valores o principios éticos. En la solidaridad y la fraternidad, la libertad y la igualdad, la participación social y la justicia con los pobres, en la vida y dignidad sagradas de los seres humanos. De lo contrario, como está ocurriendo hoy, está al acecho los diversos totalitarismos y fascismos.

Los fundamentalismos y extremismos, sean ideológicos, de derecha o de izquierda, religiosos, etc. Las desigualdades sociales-mundiales e injusticias globales entre los ricos y los pobres, en forma de paro y explotación laboral, empobrecimiento creciente y exclusión social, hambre y miseria que son los principales problemas de la humanidad. Y además, por más que sea necesario moralmente reconocer y luchar contra este conflicto social, violencia primera, entre los estratos más ricos y su injusticia estructural, violenta que empobrecen a la mayoría de la humanidad, lo social y político no se puede construir en la clave de amigos y enemigos.

No se puede hacer desde el odio, la venganza o la violencia del tipo que sea. Los fines y medios de la política deben ser morales, pacíficos, no violentos y nunca está justificado denigrar, acosar y violentar al otro, de la forma que sea. Lo cual llevaría a más violencia e injusticia, a conflictos bélicos y guerras... La historia y, nuestro caso, la fe así nos lo muestra.

\section{NUEVAS PERSPECTIVAS: NEUROCIENCIAS Y FILOSOFÍA DEL DERECHO DESDE LO IGNACIANO}

La Universidad Loyola Andalucía ha creado el Laboratorio de Neurociencia Humana, que se enmarca en el fuerte compromiso que ha adquirido esta Universidad con la excelencia en la investigación. En donde se busca una investigación de calidad, con un marcado impacto 
social y con la intención última de mejorar la calidad de vida de las personas. Asimismo, el director del Departamento de Humanidades y Filosofía de la Universidad Loyola Andalucía, Juan Antonio Senent, ha intervenido en el congreso "Modernityand the Variety of Reformations» con la ponencia "Ignatian Modernity as another modernity».

Celebrado en la Facultad de Teología de la Universidad de Viena y coorganizado por el grupo de investigación «Religion and Transformation in Contemporary European Society» de la Universität Wien y la holandesa Radboud Universität Nijmegen, el profesor Senent desarrolló las líneas principales y diferenciales que articula la tradición ignaciana en el contexto moderno. Su ponencia sobre es fruto de la investigación desarrollada en el Departamento de Humanidades y Filosofía de la Universidad Loyola Andalucía sobre la «matriz cultural ignaciana y giró sobre la propuesta cultural que nace desde la tradición espiritual ignaciana en Europa a partir del Renacimiento», explica el profesor Senent.

Creemos que estas investigaciones y acciones universitarias pueden contribuir al desarrollo humano e integral de las personas y pueblos, a una educación y formación global que posibilite el bien común. Efectivamente, los estudios de neurociencias en dialogo con la filosofía y la teología, con la tradición cristiana e ignaciana nos presentan toda una antropología y ética cualificada, integral. Un ser humano que se constituye en lo más profundo de su ser, pensar y actuar desde una vida afectiva y espiritual, con las experiencias, sentimientos y valores que nos humanizan y liberan globalmente.

El ser humano está conformado por el amor y la cooperación solidaria, por la empatía o compasión y justicia hacia los otros, por el compromiso y responsabilidad moral ante el sufrimiento e injusticia que padece el otro. El ser humano se realiza en esta vida espiritual, ética y social en el don y alteridad de los otros y del Otro, en la interrelación con los otros seres humanos, con la naturaleza o creación y con Dios. Las personas van logrando el sentido y la felicidad de la existencia en el servicio de la fe, de la cultura y de la justicia liberadora con los pobres, encarnada en la realidad social e histórica. La persona es movida por los afectos del corazón, por la razón cordial.

Esta antropología y ética, inspirada en la espiritualidad, busca las mediaciones e instituciones culturales, sociales o políticas para el bien más universal, para que la fraternidad solidaria y justicia con los pobres sean efectivas, transformadoras. La compasión, el amor y la ética es constitutivamente pública, social y política ya que pretende el bien común y la justicia con los pobres, que se vaya transformando o 
renovando las relaciones e instituciones, las leyes y las estructuras sociales e internacionales, los sistemas políticos y económicos. Las normas, leyes y sistemas solo son legítimas y justas si responden a la auténtica naturaleza del ser humano, a esta antropología y ética que promueve el bien común y la justicia con los pobres, la dignidad y derechos humanos, la vida y protagonismo de las personas. Cualquier ley o norma que no se ajuste a la vida y dignidad del ser humano, que no sea justa e impida la ética del bien común: no hay que obedecerla; antes bien, hay que resistirlas cívica y pacifícamente, oponerse a ella y buscar otras más justas, más éticas.

Esta antropología y ética integral abarca e incluye todas las dimensiones del ser humano como lo espiritual y lo material-físico o corpóreo, lo personal y lo sociopolítico. Y, por tanto, fundamenta muy bien los derechos humanos, sociales y de los pueblos que han de guiar a toda ley o sistema en la búsqueda del bien común. Tales como la vida y las libertades civiles, la alimentación y el agua, la educación y la salud o sanidad, el desarrollo humano-ecológico y la paz, un trabajo digno y la vivienda o el resto de infraestructuras que efectúan el bien común y la justicia. En la ética de la fraternidad universal y en nuestra era global, esto supone unas leyes y autoridades mundiales, internacionales que hagan posible la civilización del amor, la globalización de la justicia, de la paz y del desarrollo sostenible; frente a la globalización neoliberal del capital y del mercado libre como ídolo, de la guerra y de la destrucción ecológica.

La ética ha de orientar a las leyes y a la política para el bien común que a su vez, en el protagonismo democrático de las personas y pueblos, ha de regular y controlar a la economía para que sirva a las necesidades vitales de los seres humanos. Hay que asegurar y promover los valores o principios éticos y claves sociales, para que configuren las leyes u ordenamientos jurídicos en el bien común, la dignidad y la justicia con los pobres. Tales como el destino universal de los bienes que tiene la prioridad sobre la propiedad ya que esta última, debido a su carácter social, solo es legítima si realiza esta equidad y justa distribución de los recursos o bienes, destinados en común a toda la humanidad.

Ello requiere la pobreza evangélica en solidaridad liberadora con los pobres de la tierra, que va en contra de los ídolos de la riqueza y del tener, del ser rico, que esclavizan y oprimen al ser humano. El trabajo decente, la dignidad del trabajadora y sus familias con un salario justo, que está por encima del capital y que solo es moral si asegura todas estas condiciones laborales y humanizadoras. Es una em- 
presa y economía cooperativa, social y democrática, desde el don y solidaridad, donde los trabajadores sean los protagonistas y gestores de la vida empresarial. Como nos enseña todo lo anterior la tradición ignaciana y su pensamiento social, la Doctrina Social de la Iglesia, y está mostrando el Papa Francisco con su enseñanza, por ejemplo, en su última encíclica Laudatio SI.

\section{CONCLUSIÓN, HORIZONTES. FILOSOFÍA SOCIAL Y ÉTICA DE LA SOLIDARIDAD}

Los sectores apostólicos de la Compañía de Jesús en España han impulsado una reflexión compartida, con un significativo documento titulado "Crisis de la solidaridad, solidaridad ante la crisis». Con motivo de este interesante e importante documento, a continuación queremos comentar, reflexionar y exponer una serie de claves y criterios al servicio de la fe y de la justicia, del bien común y de la solidaridad liberadora con los pobres de la tierra.

La solidaridad es actualmente una clave esencial para comprender la filosofía y el pensamiento social, para la ética y una antropología integral. Tal como se manifiesta, asimismo, en la Doctrina Social de la Iglesia (DSI). Por ejemplo, en el magisterio de Juan Pablo II con la Sollicitudo Rei Socialis (SRS), conocida como la encíclica de la solidaridad, donde el Papa presenta de forma profunda el sentido y significado de la solidaridad.

Lejos de ser una moda y un acto puntual o pasajero, la solidaridad es el proyecto ético y antropológico que realiza las constitutivas dimensiones humanas y morales, sociales y espirituales de la persona. La solidaridad es un valor y virtud moral, humana y cristiana que es esencial en la existencia. Es el proyecto de vida que nos religa a los otros y que, de forma constante (firme y perseverante), nos llama a la responsabilidad y compromiso por el bien común, por la fraternidad y la justicia liberadora con los pobres de la tierra. Lejos de toda imposible neutralidad e imparcialidad, la solidaridad opta y se compromete asimétricamente con los sufrimientos e injusticia que padecen los empobrecidos y oprimidos, se encarna e implica con las asimetrías, desigualdades y dominación que sufren los excluidos y víctimas de la historia.

La solidaridad no es solo compartir de lo que me sobra, sino hasta de lo necesario para vivir. Se vive en la pobreza solidaria compartiendo la vida, los bienes y las luchas con los pobres de la tierra, frente a 
los ídolos del poder y del poseer, del tener y de la riqueza, de ser rico, que deshumanizan y esclavizan en la insolidaridad. Es asumir solidariamente las condiciones, causas y proyectos liberadores de los empobrecidos en el mundo que, como sujetos y protagonistas de la historias, buscan su promoción y liberación integral. Por tanto, la solidaridad es la forma de vivir, conocer y comprender, la clave epistemológica y hermenéutica, para desvelar la realidad, para asumir la verdad real en los padecimiento y anhelos de los crucificados por el mal e injusticia en la historia.

Un conocimiento de la realidad y verdad que se hace praxis por la justicia liberadora con los pobres, que confía en el futuro y la esperanza de que las causas de los oprimidos, la justicia y la solidaridad con las víctimas de la historia, vencerá a todo mal, muerte e injusticia.

La solidaridad pretende, pues, una acción y cambio social integral. La conversión personal, el cambio de mentalidad, actitud y corazón que nos lleva a la fraternidad solidaria, a la lucha por la paz y la justicia, a la pobreza liberadora de los ídolos del poder y de la riqueza, del individualismo y del egoísmo. Y por tanto, a la misma vez de forma inseparable e inter-relacionada, nos lleva a la responsabilidad y compromiso por la transformación de las relaciones deshumanizadas e injustas, de las estructuras sociales de pecado, perversas, de los sistemas políticos y económicos opresores que causan el mal común.

Como se observa, la solidaridad siempre defiende la vida y dignidad sagrada e inviolable de las personas, promueve los derechos humanos como son los políticos y sociales, los económicos y ecológicos, los culturales y religiosos. Lo que supone e implica, pues, el servicio y compromiso por el derecho al destino universal de los bienes, por la justa distribución de los recursos para toda la humanidad que hagan posible el bien común, que está por encima del derecho secundario de la propiedad.

La fraternidad y solidaridad con los pobres, entonces, lleva ineludiblemente a responsabilizarse y comprometerse por el estado social de derechos que posibilite esta equidad y justicia en el reparto de los bienes. Por la dignidad del trabajo y de los trabajadores, para que haya trabajo para todos en un reparto equitativo, y un empleo decente frente al trabajo basura, precario e indecente.

Con unas relaciones laborales humanizadas como es un trabajo estable, un salario justo, unas jornadas de trabajo humanizadoras que permitan conciliar la vida familiar con la laboral, y el resto de derechos sociales, laborales y humanos. 
Por un sistema fiscal justo, donde contribuyan y paguen más los que más tienen, las rentas más altas y el capital, las empresas multinacionales y financieras-bancarias con sus operaciones bursátiles, financieras, etc. erradicando por tanto los paraísos fiscales y demás fraudes tributarios. Por los servicios públicos que aseguran los derechos humanos. Tales como una renta básica necesaria para la dignidad del ser humano.

La universalidad y calidad de la educación y cultura, de la sanidad y medicamentos. Una vivienda digna e infraestructuras o equipamientos básicos. Los servicios sociales generales y específicos para la infancia, la familia y la mujer, las personas con diversidad funcional, etc. Esta solidaridad, en el compromiso por el estado social de derechos, requiere transformar nuestro modelo económico financiero-especulativo, y dar paso a una economía real que promueva la inversión ética para la empresa y la economía social o cooperativa, para el empleo de calidad y el desarrollo sostenible.

\section{Regulación ética de la economía}

En esta línea, se trata de transformar este modelo de economía basada en el beneficio y competitividad, dando lugar a un sistema económico humanizado cimentado en la cooperación solidaria, en la equidad y en el don de la gratuidad. Lo que conlleva, necesaria y sustancialmente, la regulación ética-política de la economía y del mercado por parte de los estados y de las sociedades civiles, de la ciudadanía cosmopolita en una democracia global. Para evitar así toda esta especulación y usura financiera, que provoca las crisis permanentes y el perpetuo e injusto endeudamiento de las familias, pueblos y personas.

Las finanzas mundiales, el comercio internacional y el sistema laboral global deben ser controlados, regulados por la ética y la política cosmopolita, por las leyes e instituciones planetarias que establezcan una mundialización de la solidaridad y de la paz, de la justicia y del desarrollo sostenible-ecológico.

Frente a la actual globalización neoliberal del capital y de la guerra, del consumismo y de la destrucción ecológica: que cada vez más produce mayor desigualdad e injusticia social-global y ambiental; que expulsa e inmoviliza a los parias de la tierra, como son los refugiados e inmigrantes, se les niega un futuro digno y la misma vida.

Y mientras, el mercado y al capital, convertidos en ídolos, se les deja circular libremente sacrificando, en el altar del beneficio, a los 
pueblos, causando crisis permanentes, arruinando economías y países, la misma vida de los pueblos y del planeta. Por todo ello, la solidaridad real e inteligente conoce y comprende bien que la actual ideología del (neo)-liberalismo economicista e individualista y el sistema del capitalismo son, por naturaleza, injustos, inhumamos e insostenible.

Tal como hemos expuesto hasta aquí, las claves y principios de la solidaridad se oponen a la misma entraña del capitalismo con su antropología y ética liberal-individualista. Ya que falsea la libertad con su individualismo insolidario, impone la propiedad, el capital y los medios de producción, como ídolos (falsos dioses) sobre los criterios básicos de la solidaridad y la justica. Como son el destino universal de los bienes, la dignidad del trabajo y la socialización de la vida empresarial-económica. Como indicamos al principio, todo lo expuesto hasta aquí se encuentra en lo más valioso de la filosofía social y de la misma DSI.

\section{REFERENCIAS BIBLIOGRÁFICAS}

ÁLVAREZ, P. (2.002), Comunidades de solidaridad. Bilbao: Mensajero.

DE LA TORRE RANGEL, J. A. (2005), Iusnaturalismo, personalismo y filosofía. Sevilla: MAD.

GÓMEZ ADANERO, M. (2014), Filosofía del derecho. Madrid: UNED.

PÉREZ LUÑO, A.E. (2007), Trayectorias contemporáneas de la filosofía y la teoría del derecho. Madrid: Tebar.

SANIGENETI, J. J. (2014), Neurociencias y filosofía del hombre. Madrid: Palabra.

SOLS LUCÍA, J. (2013), Cincos lecciones de pensamiento social cristiano. Madrid: Trotta.

VIDAL, M. (1996), Para comprender la solidaridad. Estella: Verbo Divino. 
